\title{
Prolonged Remission in SLE Revisited: An Old Wine in a New Bottle
}
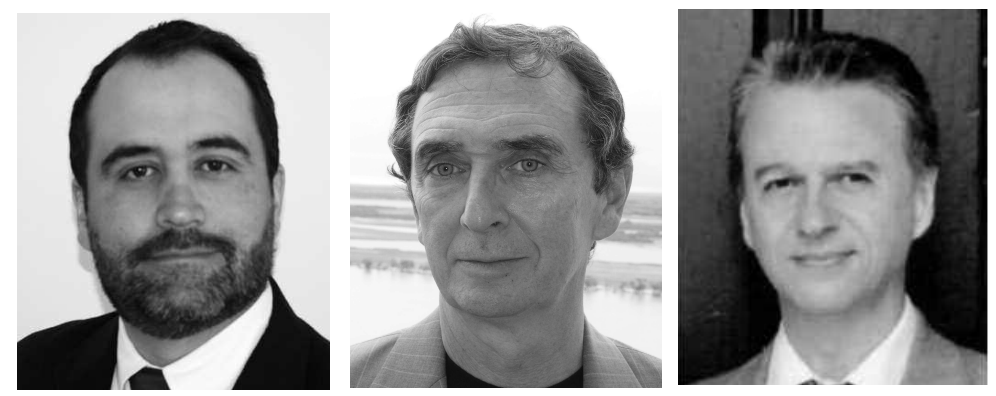

To achieve sustained remission is the ultimate goal of any maintenance treatment used in systemic lupus erythematosus (SLE) - as well as the dream of any clinician in charge of patients with SLE. While in other autoimmune diseases, such as rheumatoid arthritis, it is easier to identify which patients achieved remission or low disease activity levels, the concept of remission is more difficult to define and harder to achieve in SLE, owing to the heterogeneity of this condition, the multiple organs affected, and the many activity scores used.

In this issue of The Journal, Steiman, et al ${ }^{1}$, from the University of Toronto Lupus Clinic, interestingly revisit the concept of sustained and prolonged remission in patients with SLE followed between 1970 and 2011 using a standardized protocol at clinic visits. The authors conducted a study focused on prolonged clinical remission (clinically quiescent), with or without serological activity, in a cohort including more than 1600 SLE patients with a very long followup (mean disease duration, $21 \mathrm{yrs}$ ). Of interest, only around $2 \%$ of patients achieved prolonged (at least $5 \mathrm{yrs}$ ) clinical remission, without any underlying immunosuppressive drug (except for antimalarials). An additional subset of patients who achieved remission while taking medical treatment are described.

The authors used very strict definition criteria for serologically and clinically quiescent disease: at least a 5 -year period without evidence of clinical activity [SLE Disease Activity Index $2000($ SLEDAI-2K) = 0]. Clinically quiescent but serologically active disease allowed SLEDAI-2K scores $\leq 4$, positive anti-dsDNA antibody and/or hypocomplementemia only. Patients with prolonged remission had a lower burden of disease activity and disease damage. Further, the authors made an attempt to identify predictors of prolonged remission. Interestingly, regression models revealed that patients with late disease onset and those with less skin disease were more likely to achieve remission. As the authors recognized, caution must be taken for the interpretation of regression models, given the sample size and the limited number of outcomes included in the model.

Their study has several strengths, including the large number of patients followed in a single center with substantial experience in SLE, the longterm followup, and the very strict definition of prolonged remission. However, there is concern regarding the external validity of the findings, given the very low prevalence of African American and Hispanic patients in the present cohort. Additionally, it is important to consider the universal medical care coverage of the Canadian population because of the clear relationship that exists between lower socioeconomic status and worst prognosis as described in cohorts from countries with non-universal coverage.

The main message of this study is that some patients with SLE can achieve prolonged and sustained remission only under antimalarial treatment. However, it should be noted that just $2 \%$ of the patients could do so. Is the glass half full or half empty? The bad news is that only a small proportion of patients achieved this goal; the good news is the fact that, despite high levels of disease activity or severe organ involvement at onset (i.e., renal or neurological involvement), some patients are able to achieve a sustained remission.

Although this is a very interesting concept, scarcely explored in SLE, it is not new and has been discussed for more than 50 years. In 1964, Dubois and Tufanelli ${ }^{2}$, after analyzing over 500 patients with SLE, reported that a significant proportion of patients (around 35\%) achieved remission. However, only 9 patients achieved sustained remission for 10 to 20 years.

It is important to consider the historical context of the cohort, because the diagnosis of SLE was made based on the presence of LE cells, skin or renal biopsy, and clinical manifestations suggestive of this disease. In 1979, Gladman, et $a l^{3}$ evaluated for the first time the concept of

\section{See Prolonged clinical remission in SLE, page 1808}


sustained clinical remission. In their cohort of 180 patients, $7.7 \%$ achieved remission for a period of 4.5 years, and only 2 patients were receiving concomitant therapy with nonsteroidal antiinflammatory drugs (NSAID). In 1982, Tozman, et $a l^{4}$ reported that 4 out of 160 patients in their cohort achieved sustained remission, defined as the absence of both clinical and serological activity without immunosuppressive treatment. In 1985, Heller and Schur ${ }^{5}$ from Brigham and Women's Hospital, Boston, USA, described 13 out of 305 patients (4\%) with SLE who developed a combined clinical and serological (seroconverting from positive to negative antinuclear antibodies) remission, with duration ranging from 6 months to 13 years. Of the 13 patients who went into remission, 8 were receiving no therapy. Drenkard, et $a l^{6}$, in a cohort of 667 Mexican patients, reported that $156(23.4 \%)$ were able to achieve remission, defined as at least 1 year without clinical activity, thus allowing withdrawal of all treatment for SLE, including NSAID. Changes in disease activity markers were allowed in this period of remission, as long as clinical features were absent. Interestingly, half the patients were at least 5 years in remission, and many patients had active disease in the initial period followed by long remission periods. In 2005, Urowitz, et $a l^{7}$, using a strict definition for prolonged complete remission (at least 5 years with clinical and laboratory quiescence in the absence of immunotherapy), reported that 46 out of 703 patients $(6.5 \%)$ completed criteria for remission for at least 1 year, whereas only 12 patients (1.7\%) had prolonged remission after at least 5 years without treatment.

Data from these studies generate many questions: Are we able to identify which patients will achieve remission based on baseline characteristics at onset? Which clinical patterns follow those patients who achieve remission? Or, should we treat patients who are asymptomatic but have serologically active disease?

Some studies have reported significant differences between patients who achieved remission and those who did not. Steiman, et $a l^{8}$ reported that those patients who achieved remission were more frequently white, had lower prevalence of steroid and immunosuppressive drug use, and had lower disease activity score. Conversely, Formiga, et $a l^{9}$, in white European patients, reported no differences between patients with or without remission in baseline characteristics, including SLE-specific organ involvement or SLEDAI values.

It is well-known that white patients have a milder disease, compared to those with African ancestry ${ }^{10}$ or to Hispanics ${ }^{11}$. The GLADEL (Grupo LatinoAmericano De Estudio de Lupus, Latin American Group for the Study of Lupus) cohort is a well-defined group of Latin American patients with SLE from 9 countries with a disease diagnosis of $\leq 2$ years at entry ${ }^{12}$. Remission rates were evaluated in the GLADEL cohort, defining remission as clinical SLEDAI $=0$ for at least 1 year, regardless of immunological activity and without use of steroids and/or immunosuppressive drugs. One- and 3-year remission rates were found in $20.2 \%$ and $9.7 \%$, respectively. White patients had higher 1- and 3-year remission rates than nonwhite patients $(26.9$ vs $15.1 \%$, p < 0.001 and 14.2 vs $5.8 \%, \mathrm{p}=0.001$, respectively; unpublished data). In particular, white patients had higher remission rates than Mestizo patients (26.9 vs $14.8 \%$, p < 0.001 and 14.2 vs $5.9 \%, \mathrm{p}=0.004$, for $1 \mathrm{yr}$ and $3 \mathrm{yrs}$, respectively). Further analyses are needed to determine whether these differences are explained only by race and ethnicity, or by other factors.

Steiman, et $a l^{1}$ described 3 different disease patterns: An unusual group with monophasic disease that occurs in a minority of patients, a relapsing-remitting group, and a chronic active group. Disease patterns have also been described by other authors. Zen, et al ${ }^{13}$ analyzed disease patterns in a single center cohort and described 4 different patterns: a group with clinically quiescent disease (SLEDAI-2K = 0 in 3 annual visits); another with chronic active disease (SLEDAI-2K $\geq 2$ in at least 2 out of 3 annual visits); a third group with relapsing-remitting course (SLEDAI-2K $\geq 2$ in 1 out of 3 annual visits); and a fourth pattern with minimal persistent disease activity (SLEDAI-2K = 1 in 1 or more annual visits). It is important to consider that classification of clinical patterns is arbitrary on many occasions, and some patients jump from one pattern to another, with some periods of long quiescent disease and some periods of active intermittent/chronic activity. Independently of the clinical pattern, the treatment of flares is crucial. Recently, GLADEL has demonstrated that the number of flares that a patient experiences has an important effect on subsequent damage accrual, even if those flares are mild or moderate ${ }^{14}$. A schematic division of different clinical patterns is presented in Figure 1.

Following the recent treat-to-target guidelines for SLE generated by an international task force ${ }^{15}$, it is not recommended that treatment in clinically asymptomatic patients be escalated based solely on stable or persistent serological activity. Information from 2 randomized clinical trials focused on the prevention of severe SLE flares with the anticipated use of steroids has demonstrated some benefits, but results are not conclusive. In the first trial ${ }^{16}$, conducted almost 20 years ago on patients clinically inactive but with high levels for anti-dsDNA antibodies, those who received preventive treatment with steroids versus conventional treatment had an overall lower rate of relapses. However, no differences were found in major relapses between groups. More recently, Tseng, et $a l^{17}$ conducted another trial in patients who were assigned to receive placebo or daily prednisone (30 mg/day with tapering doses). In the placebo group, 6 out of the 20 patients $(30 \%)$ experienced a severe flare, but in the prednisone group, none of the 21 patients experienced a severe flare. Although the idea of anticipating

Personal non-commercial use only. The Journal of Rheumatology Copyright @ ${ }^{2014}$. All rights reserved 


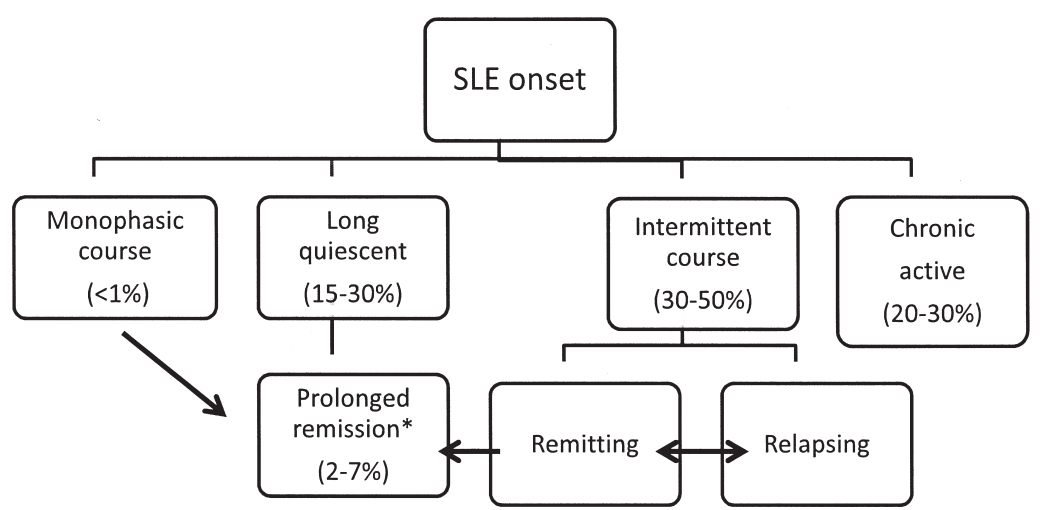

Figure 1. Patterns of SLE disease activity. *Definition of prolonged remission varies among studies. In most of the cases, prolonged remission is defined as at least 1 year in remission. Data derived from Steiman, et $a l^{1}$; Urowitz, et $a l^{7}$; Zen, et $a l^{13}$; and Barr, et $a l^{22}$. SLE: systemic lupus erythematosus.

flares in susceptible patients is attractive, the risk of overtreating asymptomatic patients should be considered.

Conversely, there is enough information to consider the benefit of the use of antimalarials in patients with clinically quiescent and serologically active disease. Antimalarials are useful not only for the prevention of flares and organ damage, including renal involvement ${ }^{18}$ and thrombosis ${ }^{19}$, but also for increasing longterm survival ${ }^{20,21}$.

Steiman and colleagues have shown us how difficult it is to obtain a prolonged remission in patients with SLE, but information about predictors of remission is still scarce. It is imperative, therefore, to develop definition(s) of remission in SLE that can be universally accepted and used both in epidemiological cohort studies and clinical trials. This is even more important if the treat-to-target strategy is going to be implemented because its first recommendation is that treatment target of SLE should be remission of systemic symptoms and organ manifestations ${ }^{15}$.

JOSE A. GÓMEZ-PUERTA, MD, MPH, PhD,

Division of Rheumatology,

Immunology and Allergy, Section of Clinical Sciences, Brigham and Women's Hospital,

Boston, Massachusetts, USA.

BERNARDO A. PONS-ESTEL, MD,

Division of Rheumatology,

Hospital Provincial de Rosario,

Rosario, Santa Fe, Argentina.

RICARD CERVERA, MD, PhD, $\mathrm{FRCP}$

Department of Autoimmune Diseases,

Hospital Clinic,

Barcelona, Catalonia, Spain.

Dr. Gómez-Puerta received support from the Fundación Alfonso Martín Escudero and received the award "Fernando Chalem" from the Colombian Society of Rheumatology.

Address correspondence to Dr. Gómez-Puerta, Division of Rheumatology, Immunology and Allergy, PBB-B3; Section of Clinical Sciences, Brigham and Women's Hospital, 221 Longwood Ave., 3rd floor, Boston, Massachusetts 02115, USA.E-mail: jgomezpuerta@mail.harvard.edu

\section{ACKNOWLEDGMENT}

We are grateful to Manuel F. Ugarte-Gil, MD, and Daniel Wojdyla, MSc, for providing expert assistance with GLADEL database analysis.

\section{REFERENCES}

1. Steiman A, Urowitz MB, Ibanez D, Papneja A, Gladman DD. Prolonged clinical remission in patients with systemic lupus erythematosus. J Rheumatol 2014;41:1808-16.

2. Dubois EL, Tuffanelli DL. Clinical manifestations of systemic lupus erythematosus. Computer analysis of 520 cases. JAMA 1964;190:104-11.

3. Gladman DD, Urowitz MB, Keystone EC. Serologically active clinically quiescent systemic lupus erythematosus: a discordance between clinical and serologic features. Am J Med 1979;66:210-5.

4. Tozman EC, Urowitz MB, Gladman DD. Prolonged complete remission in previously severe SLE. Ann Rheum Dis 1982; 41:39-40

5. Heller CA, Schur PH. Serological and clinical remission in systemic lupus erythematosus. J Rheumatol 1985;12:916-8.

6. Drenkard C, Villa AR, Garcia-Padilla C, Perez-Vazquez ME, Alarcon-Segovia D. Remission of systemic lupus erythematosus. Medicine 1996;75:88-98.

7. Urowitz MB, Feletar M, Bruce IN, Ibanez D, Gladman DD. Prolonged remission in systemic lupus erythematosus. J Rheumatol 2005;32:1467-72.

8. Steiman AJ, Gladman DD, Ibanez D, Urowitz MB. Prolonged serologically active clinically quiescent systemic lupus erythematosus: frequency and outcome. J Rheumatol 2010;37:1822-7.

9. Formiga F, Moga I, Pac M, Mitjavila F, Rivera A, Pujol R. High disease activity at baseline does not prevent a remission in patients with systemic lupus erythematosus. Rheumatology 1999;38:724-7.

10. Cooper GS, Treadwell EL, St. Clair EW, Gilkeson GS, Dooley MA Sociodemographic associations with early disease damage in patients with systemic lupus erythematosus. Arthritis Rheum 2007;57:993-9.

11. Calvo-Alén J, Reveille JD, Rodríguez-Valverde V, McGwin G Jr, Baethge BA, Friedman AW, et al. Clinical, immunogenetic and outcome features of Hispanic systemic lupus erythematosus patients of different ethnic ancestry. Lupus 2003;12:377-85.

12. Pons-Estel BA, Catoggio LJ, Cardiel MH, Soriano ER, Gentiletti S, Villa AR, et al. The GLADEL multinational Latin American prospective inception cohort of 1,214 patients with systemic lupus erythematosus: The GLADEL multinational Latin American prospective inception cohort of 1,214 patients with systemic lupus

Personal non-commercial use only. The Journal of Rheumatology Copyright $\odot$ 2014 . All rights reserved. 
erythematosus: ethnic and disease heterogeneity among

"Hispanics". Medicine 2004;83:1-17.

13. Zen M, Bassi N, Nalotto L, Canova M, Bettio S, Gatto M, et al. Disease activity patterns in a monocentric cohort of SLE patients: a seven-year follow-up study. Clin Exp Rheumatol 2012;30:856-63.

14. Ugarte-Gil MF, Acevedo-Vásquez E, Alarcón GS, Pastor-Asurza CA, Alfaro-Lozano JL, Cucho-Venegas JM, et al. The number of flares patients experience impacts on damage accrual in systemic lupus erythematosus: data from a multiethnic Latin American cohort. Ann Rheum Dis 2014; Feb 13 (E-pub ahead of print).

15. van Vollenhoven RF, Mosca M, Bertsias G, Isenberg D, Kuhn A, Lerstrøm K, et al. Treat-to-target in systemic lupus erythematosus: recommendations from an international task force. Ann Rheum Dis 2014;73:958-67.

16. Bootsma H, Spronk P, Derksen R, de Boer G, Wolters-Dicke H, Hermans J, et al. Prevention of relapses in systemic lupus erythematosus. Lancet 1995;345:1595-9.

17. Tseng CE, Buyon JP, Kim M, Belmont HM, Mackay M, Diamond $\mathrm{B}$, et al. The effect of moderate-dose corticosteroids in preventing severe flares in patients with serologically active, but clinically stable, systemic lupus erythematosus: findings of a prospective, randomized, double-blind, placebo-controlled trial. Arthritis Rheum 2006;54:3623-32.
18. Pons-Estel GJ, Alarcon GS, Burgos PI, Hachuel L, Boggio G, Wojdyla D, et al. Mestizos with systemic lupus erythematosus develop renal disease early while antimalarials retard its appearance: data from a Latin American cohort. Lupus 2013;22:899-907.

19. Ruiz-Irastorza G, Egurbide MV, Pijoan JI, Garmendia M, Villar I, Martinez-Berriotxoa A, et al. Effect of antimalarials on thrombosis and survival in patients with systemic lupus erythematosus. Lupus 2006;15:577-83.

20. Shinjo SK, Bonfa E, Wojdyla D, Borba EF, Ramirez LA, Scherbarth HR, et al. Antimalarial treatment may have a time-dependent effect on lupus survival: data from a multinational Latin American inception cohort. Arthritis Rheum 2010;62:855-62.

21. Alarcon GS, McGwin G, Bertoli AM, Fessler BJ, Calvo-Alén J, Bastian HM, et al. Effect of hydroxychloroquine on the survival of patients with systemic lupus erythematosus: data from LUMINA, a multiethnic US cohort (LUMINA L). Ann Rheum Dis 2007;66:1168-72.

22. Barr SG, Zonana-Nacach A, Magder LS, Petri M. Patterns of disease activity in systemic lupus erythematosus. Arthritis Rheum 1999;42:2682-8.

J Rheumatol 2014;41:1728-31; doi:10.3899/jrheum.140668 